\title{
Safeguarding Intangible Cultural Heritage in an Ethnic Theme Park Setting - The Case of Binglanggu in Hainan Province, China
}

International Journal of Heritage Studies

\author{
Katharina Massing
}

History and Heritage, Nottingham Trent University, Nottingham, UK

Katharina Massing, Clifton Campus, Mary Anne Evans 210, NG11 8NS, Nottingham, UK, Phone: +44 7563993913, E-mail: katharina.massing@ntu.ac.uk

I am a lecturer in Museum and Heritage Studies at Nottingham Trent University. I received my MA degree in Chinese Studies form the Free University of Berlin. I have recently received my $\mathrm{PhD}$ from Newcastle University. My thesis was titled 'Finding an ecomuseum ideal for Hainan Province: Encouraging community participation in intangible cultural and natural heritage protection in a rural setting in China'. My research interests include the safeguarding intangible cultural heritage and natural heritage, community participation, sustainable tourism and ecomuseums and community museums.

\section{Acknowledgements}

I would like to thank my supervisors Gerard Corsane and Aron Mazel for their support of my $\mathrm{PhD}$ thesis, out of which this paper has been developed. 


\section{Safeguarding Intangible Cultural Heritage in an Ethnic Theme Park Setting - The Case of Binglanggu in Hainan Province, China}

Since 2003, safeguarding intangible cultural heritage has become a priority of China's cultural heritage safeguarding policies at all levels. Despite this, academic research has paid limited attention to the safeguarding of ICH in a theme park setting. This paper examines the opportunities and challenges of safeguarding ICH in an ethnic theme park in China. It investigates how the Binglanggu theme park in Hainan aims to contribute to the safeguarding of $\mathrm{Li}$ minority heritage. The study is based on qualitative data consisting of interviews with Li minority members working at Binglanggu, the Vice-Manager of the theme park and interviews with heritage and tourism experts in Hainan, as well as observation at the theme park. The findings indicate that, when concentrating on certain ICH expressions that align with the state's ethnic minority narrative, the theme park makes an important contribution to the research and documentation of Li minority heritage. However, the park struggles to transmit ICH expressions to the younger generations. The research concludes that essential criteria to contribute to the safeguarding of ICH are to include the ethnic minority group in the safeguarding process, for example by employing them in management positions, and to concentrate more strongly on education and transmission.

Keywords: intangible cultural heritage; ICH; safeguarding; Li minority; ethnic theme parks; Hainan Province

\section{Introduction}

Ethnic theme parks or folk villages are among the most popular ethnic tourism destinations in China. They are also an important tool for safeguarding and preserving the cultural heritage and diversity of a region (Yang 2011b). However, theme parks are rarely considered for their safeguarding function. They have the reputation of contributing to the 'disneyfication' and commercialisation of cultural heritage (Oakes 1998). One ethnic theme park in Hainan, that serves as both an entertainment facility for tourists and one of the most important institutions for safeguarding Li minority heritage, 
is the 'Li and Miao Nationalities Ecological Cultural Tourist Zone in Areca Valley of Ganza Ridge' (or Binglanggu in short). While many experts in Hainan doubt the park's effectiveness in safeguarding intangible cultural heritage (ICH), interviews with Li minority members employed by the park show that its safeguarding approaches have been successful in several aspects. This paper examines the role of Binglanggu in the safeguarding the ICH of Li minority in Hainan Province, China and analyses the challenges and opportunities of safeguarding ICH in a theme park setting.

\section{Representing and Safeguarding ICH in Ethnic Theme Parks}

'Almost each minute, one kind of Chinese folk art disappears'. This quote by the Chairman of the China Folk Literature and Art Society, Feng Jicai (Zan 2007, 1), illustrates the dire situation of China's Intangible Cultural Heritage (ICH). While this statement might sound somewhat extreme, many Chinese traditional cultural-heritage practices are disappearing rapidly, often because modernisation and urbanisation are making them obsolete and destroying the original environments in which they were practised (Johnson 2014). The disappearance of ICH traditions is a worldwide issue, as impacts of globalisation and modernisation undermine cultural diversity and endanger local, regional and national traditions (Bedjaoui 2004). There is a growing mind-set that if ICH is not safeguarded it will result in an irretrievable loss of cultural heritage traditions (Howard 2012). As a result a global framework for the safeguarding of ICH was established, the 2003 UNESCO Intangible Cultural Heritage Convention (Logan 2007). ICH is defined by the 2003 Convention as:

the practices, representations, expressions, knowledge, skills - as well as the instruments, objects, artefacts and cultural spaces associated therewith - that communities, groups and, in some cases, individuals recognize as part of their cultural heritage. This intangible cultural heritage, transmitted from generation to generation, is constantly recreated by communities and groups in response to their environment, their interaction with nature and their history, and provides them with 
a sense of identity and continuity, thus promoting respect for cultural diversity and human creativity. For the purposes of this Convention, consideration will be given solely to such intangible cultural heritage as is compatible with existing international human rights instruments, as well as with the requirements of mutual respect among communities, groups and individuals, and of sustainable development. (UNESCO 2003, 1)

In other words, ICH encompasses 'heritage that is embodied in people rather than inanimate objects' (Logan 2007, 33).

The 2003 UNESCO Convention and the listing of kunqu, a form of Chinese musical theatre that originated in Southern China, as one of the Masterpieces of the Oral and Intangible Heritage of Humanity two years earlier, in 2001, triggered China's interest in actively protecting ICH. While the Chinese government had paid little attention to the safeguarding of traditional culture before, it then identified the safeguarding of ICH as a way to strengthen national unity and patriotism and to develop tourism (Pan 2008). China's ideas of safeguarding and promoting ICH are strongly influenced by the international framework; however, it also advocates several ideas that are specific to China. These ideas are expressed in the Intangible Heritage Protection Law of the People's Republic of China that came into effect on June 12011 (Pan 2008). One of the ideas that is 'China-specific' and differentiates the Chinese ICH policies from the international framework is the importance of the notion of 'excellence' (Bodolec 2012), as stated in Article 1 of the Intangible Heritage Protection Law: 'This law is formulated to inherit and carry forward the excellent traditional culture of the Chinese nation, to promote the building of the socialist spiritual civilization, and to strengthen the protection and preservation of intangible cultural heritage' (Standing Committee of the 11th National People's Congress 2011, 1).

This focus on 'excellence' differs from the 2003 UNESCO Convention. While the ideal of 'outstanding universal value' and 'excellence' is a part of the 1972 
UNESCO World Heritage Convention and was a criterion used in the Proclamation of Masterpieces of the Intangible Cultural Heritage (2001-2005), it was specifically decided not to include it in the 2003 Convention, which aimed to promote an equal recognition of diverse cultural practices (De Cesari 2012). There are no clear criteria of what constitutes 'excellence', ICH experts in China, have come to associate it with 'distinctiveness' (Chang 2016).

Another China-specific idea is the role of ICH to promote national unity and a harmonious society. It gives the national government the whole authority to decide on which ICH expressions are worth protecting and to disregard ICH that is less consistent with the current political ideology (Lixinski 2013). This diverts from the ideas expressed in the 2003 Convention in Article 15 which states that 'State Party shall endeavour to ensure the widest possible participation of communities, groups and, where appropriate, individuals that create, maintain and transmit such heritage, and to involve them actively in its management' (UNESCO 2003, 10). One part of the population whose heritage is particularly affected by this different interpretation of ICH are China's ethnic minority groups. China has 56 ethnic groups, including 55 ethnic minorities that encompass around $8.4 \%$ of the population and the Han majority that makes up $91.6 \%$. Ethnic categories were implemented after 1949 by the Chinese Communist Party as part of their modernisation and economic development plans. They defined an 'ethnic minority' as a group of people with common territory, language, economy and culture. Out of over 400 applications only 55 were accepted to fit this description (Netting 1997). Their ICH disappears especially rapidly through the pressures of modernisation and adaptation to a seemingly more sophisticated and successful Han majority. Many younger members of the ethnic minorities are leaving their hometowns and cultural traditions behind to improve their economic and social 
situation. Tian Qing $(2012,6)$, one of China's leading experts in cultural heritage protection and director of the Chinese Intangible Cultural Heritage Protection Centre, commented about the PRC's ICH policies in an interview with Ian Johnson for the New York Review of Books on the difficulties of protecting ICH in rural China as follows:

The real problem is modernization. It's worse than the Cultural Revolution. The Cultural Revolution was forced on people. But modernization is yearned for by people themselves, it's their own desire. You can't force the Miao girl to wear traditional garb. If she wants to wear jeans, she will.

The idea that the Han majority is more 'civilised', modern and that ethnic minority groups should adapt to their lifestyle is encouraged by the politics of the Chinese government that strongly influence how ethnic minority culture and their ICH traditions are represented (Harrell 1995; Oakes 1998). The state interprets ethnicminority culture to fit its own narrative and has an active interest in stereotyping and displaying minorities in a certain way. Protection efforts concentrate mainly on those expressions that conform to the official national discourse and image of these groups (Varutti 2010, 2014). The national government aims to present China as a unified and harmonious nation while at the same time reinforcing the superiority of the Han culture (Denton 2014). Protection efforts regarding ICH concentrate on heritage expressions that fit into the image of a 'happy' but 'naïve' and 'slightly backwards' and exotic ethnic minority against which Han majority can assert their own modernity (Schein 2000). This image favours heritage expressions, such as dances and handicraft and disadvantages heritage practices like languages that evolve and change over time (Varutti 2014) or religious practices that could be interpreted as superstitious (Denton 2014). Therefore, representations of ethnic minority ICH, independently of whether they are safeguarded in museums, theme parks or through other means, tend to follow a similar style (Varutti 2010). Nyíri $(2006,16)$ observed that in China: 
[c]ertain ethnicities, just like a scenic spot, acquire a standard set of cultural references: any representation of the Miao would include a tune on the lusheng pipe; Mongolians would always ride horses and wrestle; and Tibetans would always be associated with hada shawls, prayer flags, and the "eternal plateau". In summary, the Chinese government often appropriates ethnic minority culture to forge a strong national identity and develop domestic tourism, while ethnic minorities themselves have little means to show alternative representations (Denton 2014).

China's Intangible Cultural Heritage Law supports these decisions on representation by focusing on the idea of safeguarding ICH expressions that the government considers to be excellent, in addition to contributing to national unity and a harmonious society. Smith (2006) points out how international organisations and their documents, for example the 2003 UNESCO Intangible Heritage Convention, define how heritage is interpreted and managed internationally. She suggests that a document like this 'authorises heritage discourse' by representing a set of social messages mainly influenced by Western ideology. The same argument can be made for China's Intangible Cultural Heritage Law, which presents a set of values dominated by the values of the Han majority.

A third China-specific characteristic is the idea to regard $\mathrm{ICH}$ as a cultural resource with economic value. Heritage in China is often used as a tool of economic development (An and Gjestrum 1999). The Chinese Intangible Cultural Heritage Law encourages the use of ICH as a resource to develop marketable products (Standing Committee of the 11th National People's Congress 2011, Article 37). This idea is called productive protection and is aimed to boost national economic development and ICH transmission at the same time. It is a commercial approach to cultural heritage safeguarding that turns ICH resources into cultural products while maintaining their essence, integrity, and inheritance ( $\mathrm{Su} 2015)$. 
As such the law also promotes the safeguarding of $\mathrm{ICH}$ in theme park-like settings. The government has more influence to decide which ICH elements get actively transmitted and revitalised and theme parks fit well within the productive protection agenda. This is illustrated by the fact that several existing ethnic theme parks including the Yunnan Folk Cultural Villages (according to an article published on the InKunming website on June 19 2009) and Binglanggu (according to the theme park's website) have been named 'national intangible cultural heritage productive protection bases'. This term is a status that is mainly given to companies including theme parks that aim to increase the economic value of cultural heritage and safeguard it at the same time.

The approach is also adopted by newly developed theme parks with a specific ICH focus. Since 2004 China has opened several theme parks that specialise in ICH exhibitions and performances. The China (Hefei) Intangible Cultural Heritage Park in Anhui Province and the International Intangible Cultural Heritage Expo Park in Chengdu, Sichuan Province both opened in 2011 (Ye and LeGates 2013). The China (Hefei) Intangible Cultural Heritage Park displays 200 of the listed ICH expressions in China. Wang Ruisong, vice president of Anhui Huajiao Group, who initiated and funded the park explained: 'Rather than open another museum, we hit upon the idea of the Intangible Cultural Heritage Park as a more engaging and interactive means of amassing and sharing China's living cultural history with the general public' (Winterbottom 2012, 1). The park aims to attach economic value to ICH skill and actively contribute to its transmission. It does so by employing heritage transmitters and offering workshops, for example in traditional Anhui wood carving to children. Similar to other theme parks the park also has a strong focus on entertainment, including a water fountain opera display and circus performances. The theme park comprises ten 
cultural heritage demonstration zones such as artefacts, paintings, traditional Chinese medicine, opera, literature, music and dancing with an aim to become a preservation base of China's ICH and a leading tourism scenic spot (Winterbottom 2012). According to an article on the website of the People's Daily online (published 11 April 2011) the International Intangible Cultural Heritage Expo Park in Chengdu is the site of the International Intangible Cultural Heritage Festival, held every two years. Outside of the festival it serves a similar purpose to the park in Anhui as a site of ICH safeguarding, consumption and entertainment.

The concept of productive protection and the designation of 'National intangible cultural heritage productive protection bases' has been widely criticised and described as a paradox, because it cannot be guaranteed that commercialisation practices are not harmful to ICH. One criterion 'National intangible cultural heritage productive protection bases' should fulfil is authenticity, which is arguably hard to achieve in that context (Kang 2012).

The idea to display ethnic minority heritage in theme parks and the realisation that some of their ICH traditions are valuable for tourism purposes was already established in the 1990s, when ethnic minority groups became an important aspect of the domestic cultural tourism market, which was experiencing a major growth (Svensson 2006). Several ethnic-minority traditions, such as festivals, religious ceremonies and pilgrimages, ethnic plays and re-enactments of historical events have been revived for tourism purposes. As part of the ethnic tourism boom standardised and performance orientated folk villages and themes were constructed (Li and Hinch 1997; Oakes 2006; Yang and Wall 2008).

While tourism development is an important function of these theme parks, they also serve the purpose to 'preserve and revive ethnic cultures and to enhance cultural 
pride' (Yang 2011b, 317). This aspect, linked to the safeguarding and reviving of ICH traditions, has become more prominent since China ratified the 2003 UNESCO Intangible Heritage Convention in 2004 and the safeguarding of ICH was named a government priority in China's heritage protection policies. The ICH expert interviewed at Binglanggu explained:

Binglanggu started to protect ICH in 2010. This was not part of its original concept and was initiated by the provincial government in light of the UNESCO listing of Li brocade in 2009. One main measure to encourage ICH protection was to start to collect and document ICH to build an inventory.

Several authors discuss the topic of theme parks in China in regards to tourism development, modernity and the creation of a national identity (Oakes 1998, 2006; Sofield and Li 1998; Stanley 2002). The ability of ethnic theme parks to contribute to the safeguarding of ethnic-minority heritage is seldom discussed in heritage literature. The Indonesia in Miniature Park (Taman Mini) is briefly mentioned in Park (2013) for its efforts on behalf of the central and provincial government as well as the ethnic communities to safeguard ICH. The author states that the performances of traditional dance and music as well as the possibility to take traditional dance classes in the park constitutes an ICH safeguarding activity. In addition, the park records and distributes audio-visual material of traditional dances, which could be seen as ICH inventorying. The park applied for the UNESCO Register of Best Safeguarding Practices in 2014, but was not selected. Du (2005) has commented on the opportunity theme parks offer to transform ICH, such as philosophy, into physical space. Other questions discussed in the context of theme parks linked to the safeguarding of ICH concern issues of authenticity, representation and commodification of $\mathrm{ICH}$ practices. In that context, several authors argue that in ethnic theme parks cultural traditions of ethnic minorities are simplified and standardised for entertainment (Davis 2011; Denton 2014; Oakes 
1998). They aim to offer the visitors something unusual and exotic (Denton 2014).

Theme parks risk the fossilisation of culture in the sense that there is little dynamic development (Oakes 1998; Smith 2003) and to turn living cultures into mere exhibitions (Davis 2011). MacCannell (1973) described this process as 'staged authenticity' and argues that tourist performances of ethnic cultural traditions put the performers at risk of 'a distinctive form of alienation, a kind of loss of soul' (MacCannell 1992, 168).

In China, the issue of standardisation is heightened by the long history of discrimination against ethnic minorities, whose culture is perceived and portrayed as 'primitive', 'backwards' and 'exotic' in popular media and museums (Lu 2014; Varutti 2014). On account of their different kinship patterns and marriage customs, ethnic minorities in southwest China, such as the Li minority, are often characterised as sexually less restrained and eroticised. This is especially exploited by the tourism industry (Denton 2014; Hillman and Henfry 2006). In some ways, theme parks and other exhibitions of ethnic minority heritage are a symbol of cultural "otherness" (Lu 2014). It has also been observed that essential elements of cultural heritage that are deemed to be unattractive for tourist consumption, such as certain religious rituals and indigenous practices, are excluded from these parks (Yang 2011a).

All these characteristics are problematic for the safeguarding of $\mathrm{ICH}$, which needs to incorporate change, allow for traditions to be recreated and transmitted within its communities and be safeguarding in its whole diversity (Stefano 2012). ICH only exists as part of the community and its continued practice depends on the interest of its community (Blake 2009). Ethnic minority theme parks have the potential to encourage or discourage this interest.

Despite all these issues, theme parks in China do have a safeguarding function. 
Therefore, it is important to discuss their ability to contribute to the safeguarding of ICH. Overall, it can be noted that it has become more difficult to define the lines between theme parks, amusement parks, entertainment centres and museums in China (and indeed everywhere) because they all serve the purpose of entertainment, education and tourism (Ap 2003; Oakes 2006).

\section{Research Setting}

Hainan Province is located in the South China Sea, around $25 \mathrm{~km}$ off the Chinese mainland's south-western coast. Due to its long history, tropical climate and cultural diversity the island has a rich natural and cultural heritage. One group that has unique heritage traditions and is indigenous to the island is the Li minority. With a population of 1.26 million people they constitute around $15 \%$ of Hainan's total population of around 8.2 million people. The Li minority is still relatively poor and over $90 \%$ of the population work as farmers (Xie 2010). Apart from the Li minority there are also two other important ethnic minority groups; 60,000 Miao and 7,000 Hui live in Hainan. The ethnic distribution of the population is uneven; the ethnic minorities mainly live in the central-south regions of the island and the $\mathrm{Li}$ and Miao Autonomous Counties, while the Han population is concentrated along the coastal regions (Xie 2010).

Tourism is one of Hainan's main industries and its development is a priority for all levels of government. The island began its transformation into a vacation spot in 1986, when China included tourism in the national plan for social and economic development. The central government identified Hainan as one of seven priority areas for tourism development (Wang and Wall 2007). Hainan's tourism development was supported by its transition into both a province in 1988 (before that it was the administrative unit Guangdong Province) and a Special Economic Zone (Cadario et al. 1992). 
The development of tourism is still ongoing. In 2009 the central government named Hainan Province as one of the key areas to promote tourism and the State Council released the Opinions on Propelling the Construction of Hainan as an International Tourism Destination that announced the national strategy of developing Hainan into an International Tourism Island (Hainan guoji lüyoudao) by 2020 (State Council 2009).

Tourism in Hainan is very unevenly distributed. It mainly concentrates on the coastal regions around Haikou and Sanya while the interior areas receive few tourists (Stone and Wall 2003). Even though Hainan has many cultural and natural heritage resources it is mainly a beach tourism destination. Sanya's coastline in particular has seen the rapid development of recreational facilities such as luxury hotels and golf courses (Gu and Wall 2007). While the Li and Miao minority groups are widely advertised in tourism brochures, in reality Hainan makes little use of its cultural tourism resources (Xie 2003). Minorities are mainly involved in the informal tourism sector through the selling of fruits and souvenirs at the big resort areas. A small number also works in the hotel and hospitality industry (Xie 2010). At the moment the main tourism site that involves the use of $\mathrm{Li}$ and Miao culture as a tourism resource is the theme park Binglanggu, the case study of this research.

\section{Methodology}

The research employed a case-study design and qualitative data was collected from April to June 2013 in Hainan. In the case study in Binglanggu, Baoting County, 18 members of the Li minority working at the tourism zone were interviewed. The semistructured interviews were around 15 minutes long. To make the interviewees more comfortable, some of the interviews were carried out in groups of two to six participants (Bryman 2012). Overall, eight one-to-one interviews and three group interviews in two 
groups of two and one group of six Li minority members were organised. Li minority members working at Binglanggu come from all over Hainan and have very different education and income levels. Interviewees included members from the communities located around the park ( 3 interviewees), managerial staff and tour guides with university degrees (6 interviewees), as well as performers and sales staff with a highschool education (9 interviewees). The interview questions corresponded to the role ICH expressions played in their daily-life, how their ICH was safeguarded at the moment and what could be done to improve the situation. Even though the park is an Intangible Cultural Heritage Display base, most of the members of the Li minority who work there are unfamiliar with the term ICH. Therefore, in the interview questions the term 'heritage traditions' was used.

In addition, to get a better impression of how Binglanggu is managed and to get a business perspective, the Vice-Manager of Binglanggu was interviewed on its management, its aims and the working conditions of the local Li minority employees. The Vice-manager himself is a native to Guangxi Zhuang Autonomous Region. He belongs to the Zhuang minority and therefore had a first-hand understanding of the difficulties of safeguarding ethnic minority heritage. Furthermore, ten experts on ICH, tourism, museums and ethnic minorities in Hainan working as researchers and professors at Hainan Normal University, Hainan University, Binglanggu and Hainan Provincial Museum were interviewed. All of the interviewed experts belonged to the Han majority and there were few researchers belonging to the Li minority on the island. One researcher belonging to the Li minority, an expert on Li brocade, supported the research informally, but did not want to be interviewed. The semi-structured interviews were between 40 and 60 minutes long. 
Observation was also carried out in the park. The researcher was led through the park by two tour guides who also assisted in arranging the interviews. Even though the park displays both $\mathrm{Li}$ and Miao minority culture, this research focuses on the $\mathrm{Li}$ minority for two reasons: very few employees of the park are members of the Miao minority (less than 10) and the exhibition is more commercialised than the $\mathrm{Li}$ exhibition, showing few ICH expressions of the Miao.

\section{The Safeguarding of Li Minority ICH}

Many Li minority heritage traditions are slowly disappearing. While until 1949 the traditional culture of the Li minority was still practiced widely, a lot of traditional practices, such as their marriage systems or the Li tattooing systems, were forbidden by the Chinese Communist Party. The government regarded them as corrupt practices and forced the ethnic minorities to learn Mandarin Chinese and assimilate to the mainstream culture. Since 1988, with the designation of Hainan as a province and modernisation efforts from the government, the traditional life-style of ethnic minorities has been even more rapidly disappearing (Zhang and Zhan 2007). Efforts by the provincial government to preserve Hainan's ICH began with the listing of the Li textile techniques on the National Intangible Cultural Heritage List in 2006, almost parallel to the national efforts of ICH safeguarding.

These efforts are demonstrated by the creation of ICH exhibitions in two museums, in the Hainan Provincial Museum in Haikou and in the Ethnic Museum in Wuzhishan, making Hainan one of the first provinces to establish a permanent ICH exhibition in its provincial museum. The ICH exhibition in Hainan Provincial Museum displays ICH traditions of Hainan in five categories: traditional performing arts; folk customs; rituals; festivals and traditional handicraft. The Ethnic Museum concentrates 
on the ICH of Hainan's three biggest ethnic-minority groups: the Li, the Miao and the Hui.

The ICH of the Li minority receives the most attention and safeguarding work of the provincial government mainly concentrate on them. Their customs and traditions are the focus of most research and protection projects in Hainan. One research group at Hainan Normal University, for example, documents and researches the tattooing traditions of the Li minority.

Another institution that is very involved in the protection of the $\mathrm{ICH}$ of the $\mathrm{Li}$ minority is the library of Hainan University. The local documentation of Li culture is one of the library's most important projects. It began its collection work, which also includes the support of the production of academic literature, in 2004. A large part of the collection is now digitised (Zhang and Zhan 2007). A lot of Li minority ICHsafeguarding work is also conducted at Binglanggu.

According to one of the interviewed experts, most safeguarding measures of $\mathrm{Li}$ minority $\mathrm{ICH}$ are aimed at the $\mathrm{Li}$ textile techniques of weaving, dying, spinning and embroidering (also known as Li brocade). Safeguarding measures that have been established since 2006, and have been expanded when the Li textile techniques were listed on the UNESCO list of Intangible Cultural Heritage in Need of Urgent Safeguarding in 2009, have been described in detail in the listing (UNESCO 2009). According to UNESCO (2009, 30-35) these steps included the appointment of nationallevel representative practitioners by the local government and the organisation of temporary and permanent exhibitions on Li brocade. There are regular competitions on producing Li brocade and local governments set up five training centres to spread the traditional knowledge and promote the skills among the younger generation. The provincial government provides financial support for practitioners to improve their 
living conditions. Representative practitioners are responsible for the receipt of government subsidies and the organisation of training classes. Villages that are famous for their specific skills received the status of 'Villages of Li textiles'. Furthermore, governmental and non-governmental funding is provided for establishing raw material bases consisting of cotton, hemp and indigo plants that are needed to produce $\mathrm{Li}$ brocade. To promote Li brocade an archive and a databank are planned, together with an official website, exhibitions, academic research, conferences and publications. It is also planned to introduce local laws and regulations to protect this form of $\mathrm{ICH}$.

However, it is unclear how effective these methods are. The researcher visited one of 'Villages of Li textiles', Fanmao village close to Wuzhishan, in April 2012. The villagers explained that they used most of the money they received from UNESCO to build a new hall with air conditioning and a TV, where they can produce Li brocade. Fanmao village does not produce Li brocade for local use, rather it is exported abroad and most of the textiles are not spun or dyed using traditional methods. This is problematic and several Li minority members mentioned that the quality of the $\mathrm{Li}$ brocade is getting lost.

Part of the efforts to transmit the textile skills to the younger generation have included the possibility for young boys to learn the tradition, which used to be exclusively practised by women. ICH adapts and can have a flexible nature, so in theory the opening up of the heritage tradition to a wider group of potential learners is good. However, with Li brocade it does not solve the issue that the skill, which requires constant practice, is hard to incorporate into a modern life-style. While many young people start learning the skill, they often do not keep practising it. In addition, the fact that Fanmao produces Li brocade for export creates a very business-like atmosphere that attempts to preserve the skill but not the meaning behind it. 
The discussion above shows that until now few safeguarding measures regarding Hainan's ICH expressions use a holistic management approach that encourages revitalisation and change. ICH is mainly protected through museum displays, research and databases. Given that many of the protection measure regarding the Li brocade have an economic element to it, it could be argued that they fit well into the concept of productive protection and are more marketable than other ICH expressions of $\mathrm{Li}$ minority, for example, their pottery tradition, which uses less refined techniques.

\section{Binglanggu}

Binglanggu (Betel Nut Park) is an ethnic minority theme park that exhibits Li and Miao culture. It lies in Baoting Li and Miao Anonymous County, around 28km from Sanya, the county with the highest number of Li minority communities. It covers an area of about 333 hectares. The park is managed as a joint-venture between a private businessman, a member of the Han majority from mainland China and the provincial government. Since its establishment in October 1995, during the initial phase of tourism development in Hainan Province, Binglanggu went through many changes in exhibition concepts and topics (Xie 2010; Xie and Wall 2008). Xie (2010) described the changes in Binglanggu before the researcher visited the theme park in 2013. According to Xie, in early 2000 the concept of Binglanggu was to 'faithfully portray the life, customs, and conditions of the Li minority.' During that time all of the workers of Binglanggu belonged to the Li minority from the neighbouring villages and presented their knowledge of traditional skills to the visitor. Binglanggu included a small, primitive showroom displaying Li culture and history. At that time the idea behind Binglanggu was to create a living community that gave tourists the opportunity to learn more about Li culture. Even though Binglanggu was not a major tourist attraction, it received many visitors who were greatly interested in understanding Li minority culture (Xie 2010). 
According to Xie (2010) Binglanggu changed its concept in 2005. The theme park decided to place less focus on the culture of the Li and Miao minorities and concentrate on the themes of wilderness and ethnicity. From interviews with the staff and the owner Chen Tianfu, Xie (2010) identified two main reasons for this transformation. One reason was the local government aimed to develop ecotourism and wilderness tourism in the area and financially supported these changes. The other reason was that tourists started to show less interest in the Li culture and Binglanggu had to set itself apart from the competing ethnic minority theme parks closer to Sanya. To become a more attractive tourism product, Binglanggu shifted away from its previous authentic portrayal of Li minority traditions and created a new ethnic tribe, the 'Chiyou'. This fabricated tribe was understood to have originated in Northern China and to have lived primitively, similar to people in the Stone Age (Xie and Wall 2008). According to Xie and Wall (2008), tourists typically were greeted by a 'Chiyou' dressed troupe, coming out of the jungle and led on to one of the entertainments that involved the 'tribe members' killing a pig with spears. Xie $(2010,194)$ states that Binglanggu 'evolved from being a living museum focused on the Li people, to a theme park centred on the life of a cultural group found only in Chinese folklore.'

When the researcher visited Binglanggu in April 2013 the concept of the theme park had transformed again and partly returned to a more professional form of its original version. Binglanggu now centres around Li and Miao minority culture again and is a research base for Li minority culture for several national and international universities. According to an interview with the Vice-Manager of Binglanggu these changes are connected to the government's new interest in ICH protection. Binglanggu's new exhibition concept was launched when the park was named a 'national intangible cultural heritage productive protection base' in January 2010, 
shortly after the traditional Li textile technics of spinning, weaving, dyeing and embroidering were listed on the UNESCO List of Intangible Cultural Heritage in Need of Urgent Safeguarding in 2009.

While Binglanggu clearly has a commercial purpose, it also supports research about Li minority culture. Several researchers work at the park and it also liaises with universities in Hainan, China and worldwide to document and preserve Li culture. The work of the researchers at the park mainly involves the documentation of the ICH of all of the five dialect groups of the Li minority, Ha, Qi Run, Meifu and Sai that differ in traditions, traditional dress and region. They work together with the older population to record their ICH tradition. To disseminate these recordings Binglanggu published three books introducing the culture of Hainan's Li and Miao minorities. In addition, the park specialises in the collection of rare traditional cultural artefacts, for example jewellery, dresses, musical instruments etc. Binglanggu displays both Li and Miao minority culture, but its focus is on the Li minority. The main reason for this is that the park is in close proximity of several Li villages and therefore has built a relationship with the heritage transmitters living in these villages.

Binglanggu shows a mixture of exhibiting genuine heritage traditions, natural environment and fictional entertainment for the tourists. According to the Vice-Manager it is this mixture that makes Binglanggu unique:

In Binglanggu we present the visitors a display of farmers, villages and agriculture together with our friendly atmosphere. We show foreign and domestic visitors the warm-hearted culture of Hainan's Li and Miao minorities. We safeguard traditional culture, for example, we have several museum buildings that show the traditional culture of the Li minority, traditional objects and photographs. The tourists see things that are unique and that are not often displayed elsewhere. You will most likely not experience this enthusiastic, warm-hearted human relationship in other Li villages. 
Not all of the employees of the park belong to the Li or Miao minority; however, they are all dressed up in the traditional outfit of the minority that they are attempting to represent. About one third of the park employees belong to the Li minority. They are composed of the older local population living in the Li villages around the park and members of the Li and Miao ethnic minorities coming from other parts of Baoting and Hainan such as Wuzhishan, Changjiang and Lingshui. Binglanggu is divided into three different areas the cultural heritage village, the Ganza Li village and the Miao village.

The cultural heritage of the Li minority is exhibited in two areas of the valley, the cultural heritage village and the Ganza Li Village. As mentioned before, the Li minority is indigenous to Hainan Island. The religious beliefs of the Li minority are animism, ancestral worship and shamanism. The Li language has no written form and is part of the Chinese-Tibetan language family. Traditionally the Li were farmers practising swidden agriculture (Xie 2010). Instead of using the traditional Han Chinese wet paddy-fields, they planted a variety of rice that grows in dry soil. They also cultivated rice using the slash-and-burn method that is normally practised for rice growing on mountain fields (Yang 1995/1996). Their society is organised differently from that of the Han society; inheritance is passed on through the female line and their marriage customs are more open. Unlike in Han marriage tradition, in which women leave their own family to move in with their husband's family, Li women, once they reach puberty, acquire their own room called Liao which is built outside their family's house. There they can socialise with any men they like. Shortly after the wedding they return to live with their parents; however, they can continue relationships with other men until they fall pregnant (Xie 2010).

Binglanggu introduces Li culture in several museum-like exhibition halls showing Li minority heritage traditions such as pottery, textile techniques, tattoos, 
music instruments made out of bamboo or coconut, religious beliefs, fire-making and farming. Among others it shows ten ICH expressions that are listed as national ICH: firewood-chopping dance of Li nationality; primitive pottery-making technique of $\mathrm{Li}$ nationality; embroidering, spinning, weaving and dyeing techniques of Li nationality; the tree bark cloth-making technique of Li nationality and the Li people's technique of drilling wood to make fire; Sanyuesan Festival; Li clothing; musical instruments made of Bamboo; Qiongzhong area folk songs; and boat-shaped house-making techniques. It has to be noted that items on the national ICH list, which would be considered to fulfil the criteria of excellent, mainly concentrate on dance, music and handicraft. Other ICH traditions connected to their language, religious beliefs or rural lifestyle are not listed.

In the cultural heritage village the visitor first visits two halls in shape of a turtle introducing the history of the Li on Hainan Island and their religious beliefs. The next hall provides an overview of the Li culture in general displaying fire-making, pottery, Li brocade, jewellery and farming traditions and fishing with canoes. There is also one hall each dedicated to tattoos, clothing and pottery skills. Binglanggu also has Li ICH practitioners working at the park that demonstrate the skills of producing $\mathrm{Li}$ brocade, bamboo weaving and playing musical instruments such as the nose flute. These ICH practitioners live in the villages around the park and come there to work and show their heritage to the tourists. Some of the older women also still have traditional Li tattoos. In order to make the environment seem more authentic, the park has rebuilt a village for the older people to sit in. Overall, the researcher counted around 15 older Li women who know how to produce the Li brocade, eight of which still had traditional tattoos, ten men and two women who had the skill to build bamboo baskets, five men who knew how to play traditional instruments, one of them who could play a nose flute and two women who could play the gong. The interviewed researcher felt that the participation 
of these heritage practitioners was essential for Binglanggu to successfully safeguard ICH. He stated: 'Our ICH protection relies on the knowledge of the local population. Because it is their culture and we have to learn from them. Therefore, their knowledge in protecting their culture surpasses our knowledge.' The heritage practitioners at the park stated that they felt that they were making an important contribution to the wider understanding of Li culture and supported its safeguarding through their work with the researchers and tourists. Even though all of them mentioned that tourists would only get a superficial understanding of Li culture from visiting the park, they felt that it was a good start and that their contribution to research would support people to study more about Li culture in the future.

There is also a part of the village where traditional marriage customs are explained and visitors can participate in a Li marriage ceremony. The area of the Ganza Li village shows an exhibit of the different kinds of traditional Li houses. The houses are authentic houses which have been moved there from other places and have been rebuild and repaired. The houses lead to a rebuilt Li village containing traditional architectural elements.

The last area of the park is the Miao village. Binglanggu just started to expand the exhibition on Miao minority culture. It is difficult to judge the exact nature of the exhibition since the construction work was not finished at the time of the visit. However, the Miao exhibition seemed to be a lot more commercialised than the $\mathrm{Li}$ exhibition. The small part that exhibited Miao traditions displayed mainly traditional medicine and the biggest part of the Miao exhibition was focused on selling souvenirs. Regarding visitor entertainment, the park has several shows that differ in how close they come to the actual heritage traditions. One presentation shows the music traditions of the Li minority and consists of the Li people from the villages playing their instruments. 
While this kind of music would normally only be practised on special occasions, the type of music played is traditional Li music. There is also a more spectacular show of Li and Miao dances several times a day. While some of the dances are similar to the original dances, there is also a fire dance that has little to do with Li or Miao culture. The same is true for the male costumes, which were specially designed for the show. Because Li and Miao minority dances are shown together, it is sometimes difficult for the audience to distinguish which dance belongs to which minority.

The park also has a tea tasting and a zip wire ride. It sells the products produced in the park, such as the Li brocade, the bamboo baskets, jewellery, tea, typical Li minority food and alcohol as well as traditional Miao medicine. It has a wide variety of ethnic minority food, for example three types of coloured rice and a rice and meat dish wrapped in bamboo.

In regard to productive protection Binglanggu mainly concentrates on $\mathrm{Li}$ brocade. They try to attach an economic value to it by showing different patterns, its high quality and the complicated process involved in producing it. It has to be noted that Binglanggu does not actively work on transmitting ICH to younger generations. According to observation and the interview with the researcher working at the park, ICH safeguarding concentrates on inventorying and documentation.

\section{Findings and Discussion}

Interviews with Li minority members at Binglanggu showed that many of their heritage traditions are not part of their daily life anymore. Consequently, they are having to make a conscious effort to safeguard them. Three categories of ICH were mentioned that were important to the interviewees. The first category was traditions still practised by most members of the Li minority, young and old alike. The tradition most often 
named was the Sanyuesan Festival; it is held on the 3rd day of the 3rd lunar month to commemorate their ancestors. One interviewee stated that:

For me the Sanyuesan Festival is our most important tradition. It is a very happy occasion during which we can wear our traditional costumes, sing Li songs and dance traditional Li dances. During this festival we all remember our Li traditions. Other traditions mentioned by interviewees included wedding rituals, songs and dances. The second category included traditions that are still practised, but slowly declining among the younger generation; in particular among the more educated members of the Li minority. One example was the traditional Li language; one woman explained that she was never interested in learning to speak Li before she started working at Binglanggu:

For me the most important tradition is the $\mathrm{Li}$ language. I used to not like the $\mathrm{Li}$ language or be interested in learning it. There are many Li working here, so I study the Li language with them and now it is very important to me.

The third category was ICH expressions that are important for the interviewees, but are on the verge of disappearing. These traditions still prevail among the older generation, mainly women and men in their 70s, but are rarely observed among younger $\mathrm{Li}$ people, for example Li tattoos. Once an essential custom of the Li belief system, it is not practised anymore and most tattooed women are over 70 years old. Another ICH expression named in that category was the traditional Li brocade. While all of the $18 \mathrm{Li}$ minority interviewees noted the importance of Li brocade, no one from the younger generation interviewed still possesses the skill. Most of them studied it when they were younger, but are only able to do very simple patterns now. Discussions about producing $\mathrm{Li}$ brocade often revolved around its importance for Li minority culture, but also the difficulties of learning and transmitting it in the current situation. Even though interviewees felt that all of their traditions were important, many Li traditions are not part of their daily life anymore and are therefore fading into obscurity. One of the 
interviewees summarised the situation as follows: 'I feel some of our traditions are very important for the younger generation for example wedding traditions and our festivals. But I think traditional Li skills and handicraft are mainly practiced by the older generation.'

Interviews showed a deviation regarding perceptions on how effectively $\mathrm{Li}$ heritage was safeguarded. Most interviewees of the younger generation thought that $\mathrm{Li}$ heritage was well protected (11 interviewees). Two interviewees had the impression that the safeguarding of Li ICH is slowly improving, but were unsure if it was enough to effectively safeguard Li heritage traditions. One interviewee articulated that:

I think at the moment the heritage protection by the government is being strengthened very slowly. I am not really sure how to judge if it is going to be enough. Our boss and some government officials do a lot for the protection of the Li heritage at this park.

Five Li minority members, the majority of them heritage transmitters, mentioned the concern that Li ICH expressions would soon completely disappear. This feeling was expressed in the following statement:

I am not sure if my children will have the opportunity to learn about the $\mathrm{Li}$ traditions. I think in 10 or 20 years, once the older population has died, it is quite possible that we will not see most of our heritage expressions anymore.

According to most interviewees, Binglanggu is making a major contribution to the safeguarding of Li minority heritage and they mentioned the important role Binglanggu plays in researching and documenting Li culture. This impression that the owner of the park contributed a lot to ICH safeguarding was mentioned independently by many employees. It could be questioned how genuine this sentiment was, given that the interviewees livelihood depended on working at Binglanggu. However, the question leading to that statement asked about the safeguarding of Li minority heritage in general and none of the senior management was present during the interviews. It is more likely 
that before working at the park most employees had not come across the idea that their heritage should be safeguarded and therefore strongly associated it with the park and its management.

Two of the Li minority employees, who did not have much exposure to $\mathrm{Li}$ culture before working at Binglanggu, felt that working in the park and the positive attitude of the tourists does support them in regaining interest in learning about their own culture. All of the interviewees mentioned that working at the park has increased their pride in their own culture and that Binglanggu has furthered their understanding between Li minority and Han majority. This again can be contributed to the fact that before working at Binglanggu many Li minority members associated their cultural tradition with 'backwardness' and felt they were perceived as unworthy of safeguarding.

The interviewed experts saw the role of Binglanggu for the safeguarding of $\mathrm{Li}$ heritage as more critical. Even though some of them are collaborating with the theme park for their research, it was noted that the park does not focus enough on the element of change that is inherent in ICH traditions. One expert expressed: 'I feel the research and safeguarding of Li brocade would need a more contemporary element. I do not see an incorporation of the changes that are happening; they mainly concentrate on the original traditional ways of practicing the tradition.' One of the experts also expressed that the combination of tourism development and heritage protection does not work very well in Binglanggu.

Another way to protect ICH is to develop tourism, this happens for example in Binglanggu in Baoting, which is a Li and Miao minority theme park. But I feel it does not really work there, it is difficult to find the real Li culture and also the exhibitions are not quite right. I feel you do not learn enough about the daily-life of the Li population. 
This expert in particular was convinced that, in order to safeguard the whole diversity and life-style of the Li minority, safeguarding had to happen in situ, at the $\mathrm{Li}$ minority villages and involve more input of the Li minority themselves. For him, a theme park environment could never fully safeguard the diversity and complexity of $\mathrm{ICH}$.

While the interviewees belonging to the Li minority had an overall positive impression of Binglanggu's ICH safeguarding work, they also saw similar challenges to those of the experts. Ten Li minority members mentioned that some aspects displayed in the park, such as male costumes and some of the dances, are not actually part of Li culture or are highly altered. Nevertheless, none of the interviewees argued that these inaccuracies have had a negative impact on the protection work. One member of the Li minority, one of the dancers, mentioned that he felt that the dance performances encouraged people to learn more about Li culture. After his performances tourists would often talk to him to learn more about the dances. In addition, members of the $\mathrm{Li}$ minority following that line of argument were often young and not fully familiar with the complexity of Li heritage themselves. For them the dances were less meaningful and therefore their adaption to serve commercial aims made little difference to them. Furthermore, three interviewees noted that since the government started to commercialise Li minority culture, its safeguarding and its appreciation has improved significantly, an observation that fits with the government's aim of productive protection. This is articulated in the following statement:

I think the government employs a lot of our cultural heritage to improve the economy. But I feel since this is happening the provincial and the national government value our culture more. Since they started to develop the Li minority cultural heritage for tourism, there has been more research. 
Six interviewees mentioned that the safeguarding of ICH is too superficial. One member of the Li minority explained, using Li brocade as an example, how difficult it is to protect traditions deeply rooted in their unique local context with a concept aimed at protecting the $\mathrm{Li} \mathrm{ICH}$ of the whole province. In her opinion it is not possible to protect the original idea of the Li brocade because Li society has already changed too much. She stated that:

In the textile villages and factories the quality of the Li brocade is not very high. The perception, the feelings are not the same. Originally Li brocade used to be connected to our religious and cultural believes. I think the textiles are being only superficially protected. It is difficult to buy good quality Li brocade, because the skill and artistry are a family tradition that needs to be transmitted from mother to daughter. If the religious and local background is not there, it is not real $\mathrm{Li}$ brocade.

When examining the responses of the Li minority interviewees regarding which heritage traditions are important to them, it becomes evident that the safeguarding efforts of Binglanggu concentrate on the ICH expressions of the first and third category. However, the ICH expressions of the first category which included the 'Sanyuesan' festival, dances and wedding rituals are heavily exploited for tourism and often focus on the fact that Li marriage and courting customs are more open than those of the Han majority. The theme park does not invest many resources in safeguarding ICH of the second category such as the $\mathrm{Li}$ language. While most $\mathrm{Li}$ interviewees doubted that it is possible to safeguard the ICH expressions of the third category, the parks most serious safeguarding efforts revolve around them. There are two main reasons why the first and third categories that are composed of the more exotic Li traditions receive the most protection efforts. Firstly, these traditions are particularly interesting for tourism. One phenomenon of ethnic tourism in China is the 'search for the exotic in one's own backyard' (Svensson 2006, 31), which is influencing the choice of ICH that gets 
protected. Secondly, as mentioned previously, the decision of which traditions are safeguarded is also connected to political and economically reasons. The political image that contributes to national unity and pictures minorities as 'slightly backwards', however, is not how ethnic minorities want to represent themselves and therefore ICH protection is often not very effective, especially in regard to handicraft. The association of Li minority heritage with backwardness and the difficulty to fit handicraft traditions, requiring constant practice and a substantial time commitment, into a modern lifestyle were two of the main reasons why Li minority members feared many of their heritage traditions would disappear.

The different perceptions on the effectiveness of safeguarding ICH at Binglanggu can be attributed to the different understandings of what constitutes effective ICH-protection work. The younger generation, who felt that safeguarding actions should mainly consist of inventorying and documenting Li minority heritage, argued that the safeguarding of Li heritage was very effective. The older generation and experts, who associated ICH protection with transmission work in its original context, were worried about the decline of Li heritage.

It is surprising that, while experts and Li minority interviewees both notice similar challenges for the safeguarding of ICH at Binglanggu, most Li minority interviewees stated that the park made an important contribution to the safeguarding of their ICH. This has several reasons; one reason is that all Li minority members had the impression that the owner of the park was genuinely interested in Li culture and that the main purpose of the park was heritage safeguarding and not tourism development. This is also supported by the attitude that non-Li employees, such as many of the tour guides, exhibited towards Li culture. Whilst there is a focus on more exotic heritage traditions in particular during the dance performances, the tour guides did avoid using terms such 
as 'primitive' and 'backwards'. On the contrary, the guide leading the researcher through the park stressed that he was very impressed by the Li minority handicraft techniques and fire-making skills. Another reason is that tourism development and the protection of their ICH have a strong correlation for the Li minority, as it is the motivation for the safeguarding of their heritage. The issue that some heritage expressions in the park, such as the dance performances, have been adapted to make them more interesting for the visitors were seen as a chance for their safeguarding and not as contradiction. Furthermore, as Oakes (2006) argues, staged performances of ICH can be interpreted as a way for the ethnic minorities to combine tradition and modernity and therefore contribute to the safeguarding of ICH.

Nevertheless, two issues remain. Firstly, the element of change is often not present in the safeguarding of Li minority heritage and ICH expressions; for example, dance performances in Binglanggu are static without showing cultural progression (Wall and Xie 2005). Secondly, Binglanggu and other ethnic minority theme parks safeguard ICH away from its original environments and therefore take it out of context, thus representing one of its major challenges in safeguarding $\mathrm{ICH}$.

\section{Conclusion}

The findings of this paper have shown that Binglanggu offers different opportunities and challenges for the safeguarding of ICH. At the moment, Binglanggu mainly contributes to safeguarding by documenting and inventorying ICH traditions and supporting research. The park has strengthened the pride of the Li minority employees in their own culture and encouraged some of them to learn more about their ICH. But there is little effort to transmit ICH traditions to the younger generation and investment in education. Only the older generation from the surrounding villages still has the skills and knowledge to produce handicrafts and keep the Li music traditions alive. Their 
participation makes up most of the ICH in the park. Without them the main function of the park would be entertainment; this could be problematic for the future of the park. However, despite this, the park does not invest directly in the transmission of $\mathrm{ICH}$, instead making an indirect contribution. Working at Binglanggu has encouraged some members of Li minority to learn ICH skills such as the Li language. Interestingly, the park contributes to the transmission of heritage, outside the official government discourse, that contributes neither to nation building nor to economic value, simply by giving the members the opportunity to learn more about their culture. Nevertheless, the main challenge for Binglanggu is to encourage the transmission of ICH skills to younger generations. However, transmitting ICH to the younger generation is an issue for all ICH safeguarding projects in China, not only for ethnic theme parks.

In this context, it is very problematic that the government and Binglanggu only concentrate on safeguarding the traditional Li minority skills that are highly endangered, for instance Li brocade. Several Li minority members in Binglanggu were concerned that only certain aspects of their heritage have been protected, while other heritage traditions were slowly forgotten. One of the interviewees elaborated that, in her opinion, all of the Li traditions were equally important, but that only certain traditions, such as Li brocade, Li tattoos and tree bark cloth, were the focus of the protection work. To effectively protect the ICH of the Li minority it would be important to incorporate the element of change into the protection progress by including the local population and examine which heritage expressions could be integrated in a modern life-style. The key challenge for the theme park, as for most projects safeguarding ethnic minority heritage in China, is that the government's political agenda and tourism development are influencing decision-making on ICH-safeguarding. This situation is unlikely to change 
as long as non-Li people, as it is the case in Binglanggu, are responsible for safeguarding Li heritage.

Overall it can be concluded that while it is difficult to safeguard ICH, deeply rooted in the environments in which it is practised, in a theme park approach, theme parks can make a major contribution to the safeguarding of ICH. While the idea of productive protection is problematic on the one hand and supports the strong focus on handicraft, it can also be of advantage. A theme park, if successful, has a lot of financial resources available. In addition, ethnic minority groups working at the park, do have the chance to represent their own version of their cultural heritage traditions when talking to and interacting with tourists. Essential criteria to contribute to the safeguarding of ICH are to include the ethnic minority group in the safeguarding process, for example by employing them in management positions, and to concentrate more strongly on education and transmission. While Binglanggu has to work on these points, there is a reasonable assumption that they might improve in the future.

One of the most recent changes in Binglanggu, that is meant to encourage the safeguarding of Li minority ICH further, is its planned development into an ecomuseum. Initiated in France by Hugues de Varine and George Henri Rivière in the late 1960s, the ecomuseum ideal represents a locally-based, holistic approach to heritage protection and sustainable development. It calls for in situ preservation and community participation (Davis 2011). Binglanggu is one of six planned ecomuseums in Hainan Province. While Binglanggu as a reconstructed and artificially built theme park is a problematic choice for an ecomuseum as it does not fulfil one of the most important ecomuseum ideals, namely the in situ preservation of cultural heritage, it will be interesting to observe if Binglanggu will try to include the Li minority more into the ICH safeguarding process. 


\section{References}

An, L. and J. A. Gjestrum 1999. "The Ecomuseum in Theory and Practice: the first

Chinese Ecomuseum Established" Nordisk Museologi 2: 65-86.

Ap, J. 2003. “An Assessment of Theme Park Development in China.” In Tourism in China, edited by Lew, A. A., L. Yu, J. Ap and G. Zhang, 195-214. New York: Haworth Press.

Bedjaoui, M. 2004. "The Convention for the Safeguarding of the Intangible Cultural Heritage: the Legal Framework and Universally Recognized Principles." Museum International 56(1-2): 150-156.

Blake, J. 2009. “UNESCO's 2003 Convention on Intangible Cultural Heritage. The Implications on Community Involvement in 'Safeguarding.” In Intangible Heritage, edited by L. Smith and N. Akagawa, 45-73. London: Routledge.

Bodolec, C. 2012. "The Chinese Paper-Cut: From Local Inventories to the UNESCO Representative List of the Intangible Cultural Heritage of Humanity.” In Heritage Regimes and the State, edited by Bendix, R. F., A. Eggert and A. Peselmann, 249-264. Göttingen: Universitätsverlag Göttingen.

Bryman, A. 2012. Social Research Methods. 4th ed. Oxford: Oxford University Press.

Cadario, P., K. Owaga and Y. Wen. 1992. A Chinese Province as a Reform Experiment: the Case of Hainan. Washington, DC: The World Bank.

Chang, J. 2016. 'From 'Folk Culture' to 'Great Cultural Heritage of China': The Aporia of the Quest for the Essence of Chinese Culture.” In Intangible Cultural Heritage in Contemporary China. The participation of local communities, edited by Kuah, K. E. and Z. Liu, 112-136. Oxon and New York: Routledge.

Davis, P. 2011. Ecomuseums: A Sense of Place. 2nd ed. London: Continuum.

De Cesari, C. 2012. “Thinking Through Heritage Regimes.” In Heritage Regimes and the State, edited by Bendix, R. F., A. Eggert and A. Peselmann, 399-413. Göttingen: Universitätsverlag Göttingen.

Denton, K. A. 2014. Exhibiting the past: historical memory and the politics of museums in postsocialist China. Honolulu: University of Hawaii Press.

Du, D. Y. 2005. "Lun wuxing wenhuayichan de baohu yu kaifa" (Protection and development of intangible cultural heritage) Shangdong Shehui Kexue 9: 135137. 
Gu, K., and G. Wall. 2007. "Rapid urbanization in a transitional economy in China: The case of Hainan Island." Singapore Journal of Tropical Geography 28: 158-170.

Harrell, S. 1995. "Introduction: Civilising Projects and the Reaction to Them.” In Cultural Encounters on China's Ethnic Frontiers, edited by Harrell, S., 3-36. Seattle: University of Washington Press.

Hillman, B. and L. A. Henfry. 2006. "Macho Minority: Masculinity and Ethnicity on the Edge of Tibet." Modern China 32 (2): 251-272.

Howard, K. 2012. "Introduction: East Asian Music as Intangible Cultural Heritage.” In Music as Intangible Cultural Heritage: Policy, Ideology, and Practice in the Preservation of East Asian Traditions, edited by Howard, K., 1-21. Surrey: Ashgate Publishing Limited.

Johnson, I. 2012. “'Worse Than the Cultural Revolution': An Interview With Tian Qing." The New York Review of Books. http://www.nybooks.com/daily/2012/04/07/worse-cultural-revolution-interviewtian-qing/

Johnson, I. 2014. "In China, 'Once the Villages Are Gone, the Culture Is Gone"”, The New York Times, February 1. http://www.nytimes.com/2014/02/02 /world/asia/once-the-villages-are-gone-the-culture-is-gone.html

Kang, B.C. 2012. Zhongguo feiwuzhi wenhua yichan baohu fazhan baogao (Annual Development Report of Chinese Intangible Cultural Heritage Safeguarding). Beijing: Social Science Academic Press.

Li, Y. and T. Hinch. 1997. "Ethnic Tourism Attractions and their Prospect for Sustainable Development at two sites in China and Canada." Asia Pacific Journal of Tourism Research 2 (1): 5-18.

Lixinski, L. 2013. Intangible Cultural Heritage in International Law. Oxford: Oxford University Press.

Logan, W. S. 2007. “Closing Pandora's Box: Human Rights Conundrums in Cultural Heritage Protection." In Cultural Heritage and Human Rights, edited by Silverman, H. and D. F. Ruggles, 33-52. Heidelberg: Springer.

Lu, T. L. D. 2014. Museums in China: Power, Politics and Identities. Oxon: Routledge. MacCannell, D. 1973. "Staged Authenticity: arrangements of social space and time in tourist settings." The American Journal of Sociology 79(3): 589-603. 
MacCannell, D. 1992. Empty Meeting Grounds: The Tourist Papers. London:

Routledge.

McLaren, A. E. 2010. "Revitalisation of the Folk Epics of the Lower Yangzi Delta: an Example of China's Intangible Cultural Heritage." International Journal of Intangible Heritage 5: 30-43.

Netting, N. S. 1997. "The Deer Turned Her Head: Ethnic Opinions for the Hainan Li.” Bulletin of Concerned Asian Scholars 29 (2): 3-17.

Nyíri, P. 2006. Scenic Spots: Chinese Tourism, the State, and Cultural Authority. Seattle and London: University of Washington Press.

Oakes, T. 2006. "The Village as a Theme Park. Mimesis and Authenticity in Chinese Tourism." In Translocal China: Linkages, Identities and the Reimagining of Space, edited by Oakes, T. and L. Schein, 166 - 192. Oxon: Routledge.

Oakes, T. 1998. Tourism and Modernity in China. London: Routledge.

Pan, S. 2008. "Museums and the Protection of Cultural Intangible Heritage." Museum International 60 (1-2): 12-19.

Park, S.-Y. 2013. On intangible heritage safeguarding governance: an Asia-Pacific context. Newcastle upon Tyne: Cambridge Scholar Publishing.

Schein, L. 2000. Minority Rules: the Miao and the feminine in China's cultural politics. Durham: Duke University Press.

Smith, L. 2006. Uses of Heritage. London. New York: Routledge.

Smith, M. K. 2003. Issues in Cultural Tourism Studies. London: Routledge.

Sofield, T. H. B. F. M. S. Li. 1998. "Tourism Development and Cultural Policies in China." Annals of Tourism Research 25(2): 362-392.

Standing Committee of the 11th National People's Congress, 19th Session. 2011. Zhonghua renmin gongheguo feiwuzhi wenhua yichan fa (Intangible Cultural Heritage Law of the People's Republic of China). http://www.npc.gov.cn/npc/bmzz/jkww/2011-02/25/content_1628070.htm

Stanley, N. 2002. "Chinese Theme Parks and National Identity." In Theme Park Landscapes: Antecedents and Variations, edited by Young, T. and R. Riley, 269-289. Washington, D.C.: Dumbarton Oaks Research Library and Collection.

State Council. 2009. Opinions on Propelling the Construction of Hainan as an International Tourism Destination. http://www.gov.cn/zwgk/201001/04/content_1502 531.htm. 
Stefano, M. L. 2012. "Reconfiguring the Framework: Adopting an Ecomuseological Approach for Safeguarding Intangible Cultural Heritage.” In Safeguarding Intangible Cultural Heritage, edited by Stefano, M. L., P. Davis and G. Corsane, 223-238. Woodbridge: The Boydell Press.

Stone, M. and G. Wall. 2003. "Ecotourism and Community Development: Case Studies from Hainan China." Environmental Management 33 (1): 12-24.

Su, J. 2015. "Intangible Cultural Heritage (ICH) safeguarding in China.” In Sharing Cultures 2015: Proceedings of the 4th International Conference on Intangible Heritage, edited by Lira, S., R. Amoêda and C. Pinheiro, 323-328. Barcelos: Green Lines Institute.

Svensson, M. 2006. "In the Ancestors' Shadow: Cultural Heritage Contestations in Chinese Villages.” Working Paper no. 17. Stockholm: Centre for East and Southeast Asian Studies, Lund.

UNESCO. 2003. Convention for the Safeguarding of the Intangible Heritage. www.unesdoc.unesco.org.images/0013/001325/132540e.pdf.

UNESCO. 2009. List of Intangible Cultural Heritage in Need for Urgent Safeguarding. UNESCO Culture Sector. unesco-bg.org/file_store/188329e.pdf.

Varutti, M. 2010. “The Politics of Imagining and Forgetting in Chinese Ethnic Minority Museums." Outlines - Critical Practice 2: 69-82.

Varutti, M. 2014. Museums in China: The Politic of Representation after Mao. Woodbridge: The Boydell Press.

Wall, G. and P. F. Xie. 2005. “Authenticating Ethnic Tourism: Li Dancers' Perspectives.” Asia Pacific Journal of Tourism Research 10 (1): 1-21.

Wang, Y. and G. Wall. 2007. “Administrative Arrangements and Displacement Compensation in Top-down Tourism Planning - A Case from Hainan Province, China." Tourism Management 28: 70-82.

Winterbottom, V. 2012. “Living history at Hefei's 'culture park”'. Gbtimes. http://gbtimes.com/life/living-history-hefeis-culture-park

Xie, P.F. 2003. "The Bamboo-beating Dance in Hainan, China: Authenticity and Commodification.” Journal of Sustainable Tourism 11 (1): 5-16.

Xie, P.F. 2010. Authenticating Ethnic Tourism, Tourism and Cultural Change. Bristol, Buffalo: Toronto Channel View Publications. 
Xie, P.F. and G. Wall. 2008. "Authenticating Ethnic Tourism Attractions." In Managing Visitor Attractions: New Directions. 2nd ed., edited by Fyall, A., B. Garrod, A. Leask and S. Wanhill, 132-148. Oxford, UK: Butterworth Heinemann.

Yang, M. 1995/1996. "Music Loss among Ethnic Minorities in China -- A Comparison of the Li and Hui Peoples.” Asian Music 27 (1): 103-131.

Yang, L. 2011a. "Ethnic Tourism and Cultural Representation.” Annals of Tourism Research 38 (2): 561-585.

Yang, L. 2011b. "Minorities Tourism and Ethnic Theme Parks: Employees'

Perspectives from Yunnan, China." Journal of Cultural Geography 28 (2): 311338.

Yang, L. and G. Wall. 2008. "Ethnic Tourism and Entrepreneurship: Xishuangbanna, Yunnan, China.” Tourism Geographies 10 (4): 522-544.

Ye, Y. and R. LeGates. 2013. Coordinating Rural and Urban Development in China: Learning from Chengdu. Cheltenham: Edward Elgar.

Zan, J. 2007. 'More Than a Memory', Beijing Review, 41. http://www.bjreview. com.cn /special/2007-09/30/content_79727.htm

Zhang, H. and C. Zhan. 2007. “A Library's Efforts En Route to Salvaging a Vanishing Culture." Paper presented at the World Library and Information Congress: 73rd IFLA General Conference and Council, Durban, South Africa, 19-23 August 2007. 